\title{
Recommendations on the Use of Ultrasound Guidance for Adult Abdominal Paracentesis: A Position Statement of the Society of Hospital Medicine
}

\author{
Joel Cho, MD RDMS RDCS ${ }^{1}$, Trevor P. Jensen, MD MS², Kreegan Reierson, MD³ , Benji K. Mathews, MD³,4 Anjali Bhagra, MD ${ }^{5}$, \\ Ricardo Franco-Sadud, MD', Loretta Grikis, MLSㄱ, Michael Mader, MS, 8 , Ria Dancel, MD10,11, Brian P. Lucas, MD MS ${ }^{12,13}$, \\ Society of Hospital Medicine Point-of-care Ultrasound Task Force**, Nilam J. Soni, MD, MS ${ }^{8,9}$
}

\begin{abstract}
${ }^{1}$ Department of Hospital Medicine, Kaiser Permanente San Francisco Medical Center, San Francisco, California; ${ }^{2}$ Division of Hospital Medicine, University of California San Francisco Medical Center at Parnassus, San Francisco, California; ${ }^{3}$ Department of Hospital Medicine, HealthPartners Medical Group, Regions Hospital, St. Paul, Minnesota; ${ }^{4}$ Division of General Internal Medicine, University of Minnesota Medical School, Minneapolis, Minnesota; ${ }^{5}$ ivision of General Internal Medicine, Mayo Clinic, Rochester, Minnesota; ' ${ }^{D}$ ivision of General Internal Medicine, Medical College of Wisconsin, Milwaukee, Wisconsin; ${ }^{7}$ White River Junction VA Medical Center, White River Junction, Vermont; ${ }^{8}$ Divisions of General \& Hospital Medicine and Pulmonary \& Critical Care Medicine, University of Texas Health San Antonio, San Antonio, Texas; ${ }^{9}$ Section of Hospital Medicine, South Texas Veterans Health Care System, San Antonio, Texas; ${ }^{10}$ Division of Hospital Medicine, Department of Medicine, University of North Carolina, Chapel Hill, North Carolina; ${ }^{11}$ Division of General Pediatrics and Adolescent Medicine, Department of Pediatrics, University of North Carolina, Chapel Hill, North Carolina; ${ }^{12}$ Geisel School of Medicine at Dartmouth College, Hanover, New Hampshire; ${ }^{13}$ Medicine Service, White River Junction VA Medical Center, White River Junction, Vermont.
\end{abstract}

\section{EXECUTIVE SUMMARY}

1. We recommend that ultrasound guidance should be used for paracentesis to reduce the risk of serious complications, the most common being bleeding.

2. We recommend that ultrasound guidance should be used to avoid attempting paracentesis in patients with an insufficient volume of intraperitoneal free fluid to drain.

3. We recommend that ultrasound guidance should be used with paracentesis to improve the success rates of the overall procedure.

4. We recommend that ultrasound should be used to assess the volume and location of intraperitoneal free fluid to guide clinical decision making of where paracentesis can be safely performed.

5. We recommend that ultrasound should be used to identify a needle insertion site based on size of the fluid collection, thickness of the abdominal wall, and proximity to abdominal organs.

6. We recommend that the needle insertion site should be evaluated using color flow Doppler ultrasound to identify and avoid abdominal wall blood vessels along the anticipated needle trajectory.

7. We recommend that a needle insertion site should be evaluated in multiple planes to ensure clearance from underlying abdominal organs and detect any abdominal wall blood vessels along the anticipated needle trajectory. 8. We recommend that a needle insertion site should be marked with ultrasound immediately before performing the procedure, and the patient should remain in the same position between marking the site and performing the procedure.

9. We recommend that using real-time ultrasound guidance for paracentesis should be considered when the fluid collection is small or difficult to access.

10. We recommend that dedicated training sessions, including didactics, supervised practice on patients, and simulation-based practice, should be used to teach novices how to perform ultrasound-guided paracentesis.

11. We recommend that simulation-based practice should be used, when available, to facilitate acquisition of the required knowledge and skills to perform ultrasoundguided paracentesis.

12. We recommend that competence in performing ultrasound-guided paracentesis should be demonstrated prior to independently performing the procedure on patients. Journal of Hospital Medicine 2014;14:E7-E15. Published Online Only January 2, 2019 @ 2019 Society of Hospital Medicine

\footnotetext{
*Corresponding Author: Joel Cho, MD RDMS RDCS; E-mail: joel.cho@kp.org; Telephone: 415-833-5800

**Task Force Members are listed after the Conclusion

Additional Supporting Information may be found in the online version of this article.
}

Received: May 29, 2018; Revised: August 20, 2018,

Accepted: September 7, 2018

๑ 2019 Society of Hospital Medicine DOI 10.12788/jhm.3095

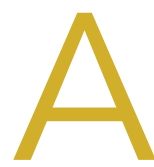
bdominal paracentesis is a common and increasingly performed procedure in the United States. According to Medicare Physician Supplier Procedure Summary Master Files, an estimated 150,000 paracenteses were performed on Medicare fee-for-service beneficiaries in 2008 alone; such a number represents more than a two-fold increase from the same service population in 1993. ${ }^{1}$ This increasing trend was again noted by the Nationwide Inpatient Sample data, which identified a $10 \%$ increase in hospitalized patients with a diagnosis of cirrhosis receiving 
paracentesis from 2004 (50\%) to 2012 (61\%; $P<.0001){ }^{2}$

Although these data demonstrate that paracentesis is being performed frequently, paracentesis may be underutilized in hospitalized cirrhotics with ascites. In addition, in-hospital mortality of cirrhotics with ascites is higher among those who do not undergo paracentesis than among those who do $(9 \%$ vs $6 \% ; P=.03) \cdot 3,4$

While complications associated with paracentesis are rare, serious complications, including death, have been document-

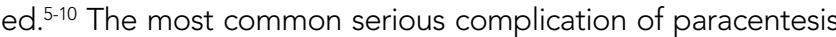
is bleeding, although puncture of the bowel and other abdominal organs has also been observed. Over the past few decades, ultrasound has been increasingly used with paracentesis due to the ability of ultrasound to improve detection of ascites ${ }^{11,12}$ and to avoid blood vessels $\mathrm{s}^{10,13-15}$ and bowels. ${ }^{16}$

Three-quarters of all paracenteses are currently performed by interventional radiologists. ${ }^{1}$ However, paracenteses are often required off-hours, ${ }^{17}$ when interventional radiologists are less readily available. Weekend admissions have less frequent performance of early paracentesis than weekday admissions, and delaying paracentesis may increase mortality., ${ }^{3,18}$ High proficiency in ultrasound-guided paracentesis is achievable by nonradiologists ${ }^{19-28}$ with equal or better patient outcomes after appropriate training. ${ }^{29}$

The purpose of this guideline is to review the literature and present evidence-based recommendations on the performance of ultrasound-guided paracentesis at the bedside by practicing hospitalists.

\section{METHODS}

Detailed methods are described in Appendix 1. The Society of Hospital Medicine (SHM) Point-of-care Ultrasound (POCUS) Task Force was assembled to carry out this guideline development project under the direction of the SHM Board of Directors, Director of Education, and Education Committee. All expert panel members were physicians or advanced-practice providers with expertise in POCUS. Expert panel members were divided into working group members, external peer reviewers, and a methodologist, and all Task Force members were required to disclose any potential conflicts of interests (Appendix 2). The literature search was conducted in two independent phases. The first phase included literature searches conducted by the five working group members themselves. Key clinical questions and draft recommendations were then prepared, and a systematic literature search was conducted by a medical librarian based on the findings of the initial literature search and draft recommendations. The Medline, Embase, CINAHL, and Cochrane medical databases were initially searched from 1975 to October 2015. Google Scholar was also searched without limiters. An updated search was conducted from November 2015 to November 2017, search strings for which are included in Appendix 3. All article abstracts were first screened for relevance by at least two members of the working group. Full-text versions of screened articles were reviewed and articles on ultrasound guidance for paracentesis were selected. The following article types were excluded: non-English language, nonhuman, age <18 years, meeting abstracts, meeting posters, letters, and editorials. All relevant systematic reviews, meta-analyses, randomized controlled trials, and observational studies of ultrasound-guided paracentesis were screened and selected. Final article selection was based on working group consensus. The selected literature was incorporated into the draft recommendations.

We used the RAND Appropriateness Method that required panel judgment and consensus to establish recommendations. ${ }^{30}$ The voting members of the SHM POCUS Task Force reviewed and voted on the draft recommendations considering five transforming factors: (1) problem priority and importance; (2) level of quality of evidence; (3) benefit/harm balance; (4) benefit/burden balance; and (5) certainty/concerns about preferences/equity acceptability/feasibility. Panel members participated in two rounds of electronic voting using an internet-based electronic data collection tool (Redcap $^{\text {TM}}$ ) during February 2018 and April 2018 (Appendix 4) and voting on appropriateness was conducted using a 9-point Likert scale. The three zones based on the 9-point Likert scale were inappropriate (1-3 points), uncertain (4-6 points), and appropriate (7-9 points), and the degree of consensus was assessed using the RAND algorithm (Appendix 1, Figure 1 , and Table 1). Establishing a recommendation required at least $70 \%$ agreement that a recommendation was "appropriate." A strong recommendation required $80 \%$ of the votes within one integer of the median, following RAND rules, and disagreement was defined as $>30 \%$ of panelists voting outside of the zone of the median.

TABLE 1. Definitions of Levels of Consensus

\begin{tabular}{ll}
\hline Term & Definition \\
\hline Perfect consensus & All respondents agree on one number between 7 and 9 \\
\hline $\begin{array}{l}\text { Very good consensus } \\
\text { within } 1 \text { integer of the median (eg, median is } 8,80 \% \text { respondents are from } 7 \text { to } 9 \text { ) }\end{array}$ \\
\hline $\begin{array}{l}50 \% \text { of respondents are within } 1 \text { integer of the median (eg, median is } 8,50 \% \text { of respondents are from } 7 \text { to } 9 \text { ) or } 80 \% \text { of the respondents are within } 2 \text { integers } \\
\text { of the median (eg, median is } 7,80 \% \text { of respondents are from } 5 \text { to } 9 \text { ) }\end{array}$ \\
\hline $\begin{array}{l}50 \% \text { or respondents are within } 2 \text { integers of the median (eg, median is } 7,50 \% \text { of respondents are from } 5 \text { to } 9 \text { ) or } 80 \% \text { of respondents at } 8 \text { ) or } 80 \% \text { of respondents are within } 3 \text { integers of the median } \\
\text { (eg, median is } 6,80 \% \text { of respondents are from } 3 \text { to } 9)\end{array}$ \\
\hline No consensus & All other responses. Any median with disagreement
\end{tabular}


Recommendations were classified as strong or weak/conditional based on preset rules defining the panel's level of consensus, which determined the wording for each recommendation (Tables 1 and 2). The revised consensus-based recommendations underwent internal and external review by POCUS experts from different subspecialties, and a final review of the guideline document was performed by members of the SHM POCUS Task Force, SHM Education Committee, and SHM Board of Directors. The SHM Board of Directors endorsed the document prior to submission to the Journal of Hospital Medicine.

\section{RESULTS}

\section{Literature search}

A total of 794 references were pooled and screened from literature searches conducted by a certified medical librarian in October 2015 (604 citations) and updated in November 2017 (118 citations), and working group members' personal bibliographies and searches (72 citations; Appendix 3, Figure 2). Final selection included 91 articles that were abstracted into a data table and incorporated into the draft recommendations.

\section{Recommendations}

Four domains (terminology, clinical outcomes, technique, and training) with 13 draft recommendations were generated based on the literature review by the paracentesis working group. After two rounds of panel voting, one recommendation did not achieve consensus based on the RAND rules, and 12 statements received final approval. The degree of consensus based on the median score and dispersion of voting around the median are shown in Appendix 5. All 12 statements achieved consensus as strong recommendations. The strength of each recommendation and degree of consensus are summarized in Table 3.
TABLE 2. Degree of Consensus, Strength of Recommendation, and Wording

\begin{tabular}{lcc} 
Degree of Consensus & Strength of Recommendation & Wording [Based on Voting] \\
\hline \begin{tabular}{lcc} 
Perfect consensus & Strong & Recommend - must/to be/will \\
\hline Very good consensus & Strong & Recommend - should be/can \\
\hline Good consensus & Weak/Conditional & Suggest - to do \\
\hline $\begin{array}{l}\text { Some consensus } \\
\text { No consensus } \\
\text { Disagreement }\end{array}$ & Weak/Conditional & Suggest - may do \\
\hline
\end{tabular} No & $\begin{array}{l}\text { No recommendation } \\
\text { was made regarding }\end{array}$
\end{tabular}

\section{Terminology}

Abdominal paracentesis is a procedure in which fluid is aspirated from the intraperitoneal space by percutaneous insertion of a needle with or without a catheter through the abdominal wall. Throughout this document, the term "paracentesis" refers to "abdominal paracentesis."

In this document, ultrasound-guided paracentesis refers to the use of static ultrasound guidance to mark a needle insertion site immediately prior to performing the procedure. Real-time (dynamic) ultrasound guidance refers to tracking of the needle tip with ultrasound as it traverses the abdominal wall to enter the peritoneal cavity. Landmark-based paracentesis refers to paracentesis based on physical examination alone.

\section{RECOMMENDATIONS}

Clinical outcomes

1. We recommend that ultrasound guidance should be used for paracentesis to reduce the risk of serious complications, the most common being bleeding.

\section{TABLE 3. Summary of Recommendations}

\begin{tabular}{|c|c|c|c|}
\hline No. & Topic of Recommendation & Strength of Recommendation & Degree of Consensus \\
\hline \multicolumn{4}{|c|}{ Clinical Outcomes } \\
\hline 1 & Ultrasound reduces risk of serious complications & Very Good & Strong \\
\hline 2 & Ultrasound avoids attempting paracentesis with insufficient fluid & Very Good & Strong \\
\hline \multirow[t]{2}{*}{3} & Ultrasound improves overall procedure success rates & Very Good & Strong \\
\hline & Ultrasound reduces cost and length of stay & N/A & N/A \\
\hline \multicolumn{4}{|c|}{ Technique } \\
\hline 4 & Assess volume and location of intraperitoneal free fluid & Very Good & Strong \\
\hline 5 & Identify needle insertion site & Very Good & Strong \\
\hline 6 & Use color flow Doppler to identify abdominal wall vessels & Very Good & Strong \\
\hline 7 & Evaluate needle insertion site in multiple planes & Very Good & Strong \\
\hline 8 & Mark the needle insertion site immediately before the procedure & Very Good & Strong \\
\hline 9 & Consider real-time ultrasound guidance for small or difficult-to-access fluid collection & Very Good & Strong \\
\hline \multicolumn{4}{|c|}{ Training } \\
\hline 10 & Dedicated training sessions recommended & Very Good & Strong \\
\hline 11 & When available, use simulation to train & Very Good & Strong \\
\hline 12 & Demonstration of competence before independently attempting the procedure & Very Good & Strong \\
\hline
\end{tabular}

$\mathrm{N} / \mathrm{A}=$ Statements without recommendations due to lack of agreement or uncertainty 
Rationale. The occurrence of both minor and serious life-threatening complications from paracentesis has been well described. ${ }^{5-10,31,32} \mathrm{~A}$ recent retrospective study that evaluated 515 landmark-guided paracenteses noted that the most common minor complication was persistent ascites leakage (5\%) and that the most common serious complication was postprocedural bleeding (1\%). ${ }^{8}$ Studies have shown that abdominal wall hematoma and hemoperitoneum are common hemorrhagic complications of paracentesis, although inferior epigastric artery pseudoaneurysm has also been described. 9,33,34

Current literature suggests that ultrasound-guided paracentesis is a safe procedure, even with reduced platelet counts or elevated international normalized ratio. ${ }^{35-42}$ Most comparative studies have shown that ultrasound guidance reduces the risk of bleeding complications compared with the use of landmarks alone, $7,31,32,43-45$ although a few studies did not find a significant difference between techniques. ${ }^{20,36,46}$ One large retrospective observational study that analyzed the administrative data of 69,859 paracenteses from more than 600 hospitals demonstrated that ultrasound guidance reduced the odds of bleeding complications by $68 \%(\mathrm{OR}, 0.32 ; 95 \% \mathrm{Cl}, 0.25-0.41)$. Bleeding complication rates with and without the use of $\mathrm{ul}$ trasound guidance were $0.27 \%(\mathrm{Cl} 0.26-0.29)$ versus $1.25 \%(\mathrm{Cl}$ 1.21-1.29; $P<.0001)$, respectively. More importantly, in this study, paracentesis complicated by bleeding was associated with a higher in-hospital mortality rate compared to paracentesis that were not complicated by bleeding (12.9\% vs $3.7 \%$; $P$ $<.0001){ }^{43}$

\section{We recommend that ultrasound guidance should be used to avoid attempting paracentesis in patients with an insufficient volume of intraperitoneal free fluid to drain.}

Rationale. Abdominal physical examination is not a reliable method for determining the presence or volume of intraperitoneal free fluid, as no specific physical examination finding has consistently shown both high sensitivity and specificity

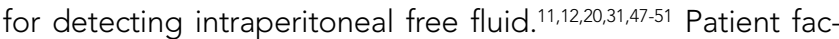
tors limiting the diagnostic accuracy of physical examination include body habitus, abdominal wall edema, and gaseous bowel distention.

In comparative studies, ultrasound has been found to be significantly more sensitive and specific than physical examination in detecting peritoneal free fluid. ${ }^{11,12}$ Ultrasound can detect as little as $100 \mathrm{~mL}$ of peritoneal free fluid, ${ }^{52,53}$ and larger volumes of fluid have higher diagnostic accuracy. ${ }^{53-55}$ In one randomized trial of 100 patients suspected of having ascites, patients were randomized to landmark-based and ultrasound-guided paracentesis groups. Of the 56 patients in the ultrasound-guided group, 14 patients suspected of having ascites on physical examination were found to have no or an insufficient volume of ascites to attempt paracentesis. ${ }^{20}$ Another study with 41 ultrasound examinations on cancer patients suspected of having intraperitoneal free fluid by history and physical examination demonstrated that only 19 (46\%) were considered to have a sufficient volume of ascites by ultrasound to attempt paracentesis. ${ }^{38}$
3. We recommend that ultrasound guidance should be used for paracentesis to improve the success rates of the overall procedure.

Rationale. In addition to avoiding drainage attempts in patients with an insufficient volume of intraperitoneal free fluid, ultrasound can increase the success rate of attempted procedures by localizing the largest fluid collection and guiding selection of an optimal needle insertion site. The success rates of landmark-based paracentesis in patients suspected of having intraperitoneal free fluid by physical examination are not well described in the literature, but multiple studies report success rates of $95 \%-100 \%$ for paracentesis when using ultrasound guidance to select a needle insertion site..$^{20,38,56,57}$ In one randomized trial comparing ultrasound-guided versus landmark-based paracentesis, ultrasound-guided paracentesis revealed a significantly higher success rate (95\% of procedures performed) compared with landmark-based parancentesis (61\% of procedures performed). Moreover, $87 \%$ of the initial failures in the landmark-based group underwent subsequent successful paracentesis when ultrasound guidance was used. Ultrasound revealed that the rest of the patients (13\%) did not have enough fluid to attempt ultrasound-guided paracentesis. ${ }^{20}$

\section{Technique}

\section{We recommend that ultrasound should be used to} assess the characteristics of intraperitoneal free fluid to guide clinical decision making of where paracentesis can be safely performed.

Rationale. The presence and characteristics of intraperitoneal fluid collections are important determinants of whether paracentesis, another procedure, or no procedure should be performed in a given clinical scenario. One study reported that the overall diagnostic accuracy of physical examination for detecting ascites was only $58 \%,{ }^{50}$ and many providers are unable to detect ascites by physical examination until $1 \mathrm{~L}$ of fluid has accumulated. One small study showed that at least 500 $\mathrm{ml}$ of fluid must accumulate before shifting dullness could be detected. ${ }^{58}$ By contrast, ultrasound has been shown to reliably detect as little as $100 \mathrm{~mL}$ of peritoneal free fluid ${ }^{52,53}$ and has been proven to be superior to physical examination in several studies. ${ }^{11,12}$ Therefore, ultrasound can be used to qualitatively determine whether a sufficient volume of intraperitoneal free fluid is present to safely perform paracentesis.

Studies have shown that ultrasound can also be used to differentiate ascites from other pathologies (eg, matted bowel loops, metastases, abscesses) in patients with suspected ascites on history and physical examination. ${ }^{16}$ In addition, ultrasound can help to better understand the etiology and distribution of the ascites. ${ }^{59-61}$ Sonographic measurements allow semiquantitative assessment of the volume of intraperitoneal free fluid, which may correlate with the amount of fluid removed in therapeutic paracentesis procedures. ${ }^{62,63}$ Furthermore, depth of a fluid collection by ultrasound may be an independent risk factor for the presence of spontaneous bacterial peritonitis (SBP), with one small study showing a higher risk of SBP with larger fluid collections than with small ones. ${ }^{64}$ 
5. We recommend that ultrasound should be used to identify a needle insertion site based on size of the fluid collection, thickness of the abdominal wall, and proximity to abdominal organs.

Rationale. When providers perform paracentesis using ultrasound guidance, any fluid collection that is directly visualized and accessible may be considered for drainage. The presence of ascites using ultrasound is best detected using a low-frequency transducer, such as phased array or curvilinear transducer, which provides deep penetration into the abdomen

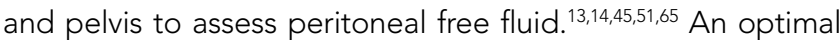
needle insertion site should be determined based on a combination of visualization of largest fluid collection, avoidance of underlying abdominal organs, and thickness of abdominal wall. $13,31,66,67$

\section{We recommend the needle insertion site should be} evaluated using color flow Doppler ultrasound to identify and avoid abdominal wall blood vessels along the anticipated needle trajectory.

Rationale. The anatomy of the superficial blood vessels of the abdominal wall, especially the lateral branches, varies greatly. ${ }^{68-70}$ Although uncommon, inadvertent laceration of an inferior epigastric artery or one of its large branches is associated with significant morbidity and mortality. $10,15,69,71-73$ A review of 126 cases of rectus sheath hematomas, which most likely occur due to laceration of the inferior or superior epigastric artery, at a single institution from 1992 to 2002 showed a mortality rate of $1.6 \%$, even with aggressive intervention. ${ }^{74}$ Besides the inferior epigastric arteries, several other blood vessels are at risk of injury during paracentesis, including the inferior epigastric veins, thoracoepigastric veins, subcostal artery and vein branches, deep circumflex iliac artery and vein, and recanalized subumbilical vasculature..$^{75-77}$ Laceration of any of the abdominal wall blood vessels could result in catastrophic bleeding.

Identification of abdominal wall blood vessels is most commonly performed with a high-frequency transducer using color flow Doppler ultrasound. 10,13-15 A low-frequency transducer capable of color flow Doppler ultrasound may be utilized in patients with a thick abdominal wall.

Studies suggest that detection of abdominal wall blood vessels with ultrasound may reduce the risk of bleeding complications. One study showed that $43 \%$ of patients had a vascular structure present at one or more of the three traditional landmark paracentesis sites. ${ }^{78}$ Another study directly compared bleeding rates between an approach utilizing a low-frequency transducer to identify the largest collection of fluid only versus a two-transducer approach utilizing both low and high-frequency transducers to identify the largest collection of fluid and evaluate for any superficial blood vessels. In this study, which included 5,777 paracenteses, paracentesis-related minor bleeding rates were similar in both groups, but major bleeding rates were less in the group utilizing color flow Doppler to evaluate for superficial vessels $(0.3 \%$ vs $0.08 \%)$; differences found between groups, however, did not reach statistical significance $(P=.07) .{ }^{79}$
7. We recommend that a needle insertion site should be evaluated in multiple planes to ensure clearance from underlying abdominal organs and detect any abdominal wall blood vessels along the anticipated needle trajectory. Rationale. Most ultrasound machines have a slice thickness of $<4$ $\mathrm{mm}$ at the focal zone. ${ }^{80}$ Considering that an ultrasound beam represents a very thin 2-dimentional cross-section of the underlying tissues, visualization in only one plane could lead to inadvertent puncture of nearby critical structures such as loops of bowel or edges of solid organs. Therefore, it is important to evaluate the needle insertion site and surrounding areas in multiple planes by tilting the transducer and rotating the transducer to orthogonal planes. ${ }^{61}$ Additionally, evaluation with color flow Doppler could be performed in a similar fashion to ensure that no large blood vessels are along the anticipated needle trajectory.

\section{We recommend that a needle insertion site should be} marked with ultrasound immediately before performing the procedure, and the patient should remain in the same position between marking the site and performing the procedure.

Rationale. Free-flowing peritoneal fluid and abdominal organs, especially loops of small bowel, can easily shift when a patient changes position or takes a deep breath. ${ }^{13,16,53}$ Therefore, if the patient changes position or there is a delay between marking the needle insertion site and performing the procedure, the patient should be reevaluated with ultrasound to ensure that the marked needle insertion site is still safe for paracentesis. ${ }^{78}$ After marking the needle insertion site, the skin surface should be wiped completely clean of gel, and the probe should be removed from the area before sterilizing the skin surface.

\section{We recommend that using real-time ultrasound guid- ance for paracentesis should be considered when the fluid collection is small or difficult to access.}

Rationale. Use of real-time ultrasound guidance for paracentesis has been described to drain abdominal fluid collections. ${ }^{13,20,62}$ Several studies have commented that real-time ultrasound guidance for paracentesis may be necessary in obese patients, in patients with small fluid collections, or when performing the procedure near critical structures, such as loops of small bowel, liver, or spleen. ${ }^{57,81}$ Real-time ultrasound guidance for paracentesis requires additional training in needle tracking techniques and specialized equipment to maintain sterility.

\section{Training}

10. We recommend that dedicated training sessions, including didactics, supervised practice on patients, and simulation-based practice, should be used to teach novices how to perform ultrasound-guided paracentesis.

Rationale. Healthcare providers must gain multiple skills to safely perform ultrasound-guided paracentesis. Trainees must learn how to operate the ultrasound machine to identify the most appropriate needle insertion site based on the abdominal wall thickness, fluid collection size, proximity to nearby abdominal organs, and presence of blood vessels. Education 
regarding the use of ultrasound guidance for paracentesis is both desired ${ }^{82,83}$ and being increasingly taught to health care providers who perform paracentesis. ${ }^{20,84-86}$

Several approaches have shown high uptake of essential skills to perform ultrasound-guided paracentesis after short training sessions. One study showed that first-year medical students can be taught to use POCUS to accurately diagnose ascites after three 30-minute teaching sessions. ${ }^{19}$ Another study showed that emergency medicine residents can achieve high levels of proficiency in the preprocedural ultrasound evaluation for paracentesis with only one hour of didactic training. ${ }^{20}$ Other studies also support the concept that adequate proficiency is achievable within brief, focused training sessions. ${ }^{21-28}$ However, these skills can decay significantly over time without ongoing education. ${ }^{87}$

\section{We recommend that simulation-based practice should be used, when available, to facilitate acquisition of the re- quired knowledge and skills to perform ultrasound-guid- ed paracentesis.}

Rationale. Simulation-based practice should be used when available, as it has been shown to increase competence in bedside diagnostic ultrasonography and procedural techniques for ultrasound-guided procedures, including paracentesis. ${ }^{22,25,29,88,89}$ One study showed that internal medicine residents were able to achieve a high level of proficiency to perform ultrasound-guided paracentesis after a three-hour simulation-based mastery learning session. ${ }^{88}$ A follow-up study suggested that, after sufficient simulation-based training, a nonradiologist can perform ultrasound-guided paracentesis as safely as an interventional radiologist. ${ }^{29}$

12. We recommend that competence in performing ultrasound-guided paracentesis should be demonstrated prior to independently performing the procedure on patients.

Rationale. Competence in ultrasound-guided paracentesis requires acquisition of clinical knowledge of paracentesis, skills in basic abdominal ultrasonography, and manual techniques to perform the procedure. Competence in ultrasound-guided paracentesis cannot be assumed for those graduating from internal medicine residency in the United States. While clinical knowledge of paracentesis remains a core competency of graduating internal medicine residents per the American Board of Internal Medicine, demonstration of competence in performing ultrasound-guided or landmark-based paracentesis is not currently mandated. ${ }^{90}$ A recent national survey of internal medicine residency program directors revealed that the curricula and resources available to train residents in bedside diagnostic ultrasound and ultrasound-guided procedures, including paracentesis, remain quite variable. ${ }^{83}$

While it has not been well studied, competence in ultrasound for paracentesis, as with all other skills involved in bedside procedures, is likely best evaluated through direct observation on actual patients. ${ }^{91}$ As such, individualized systems to evaluate competency in ultrasound-guided paracentesis should be established for each site where it is performed. A list of consensus-derived ultrasound competencies for ultra- sound-guided paracentesis has been proposed, and this list may serve as a guide for both training curriculum development and practitioner evaluation. .6, $^{11,92}$

\section{KNOWLEDGE GAPS}

In the process of developing these recommendations, we identified several important gaps in the literature regarding the use of ultrasound guidance for paracentesis.

First, while some data suggest that the use of ultrasound guidance for paracentesis may reduce the inpatient length of stay and overall costs, this suggestion has not been studied rigorously. In a retrospective review of 1,297 abdominal paracenteses by Patel et al., ultrasound-guided paracentesis was associated with a lower incidence of adverse events compared with landmark-based paracentesis ( $1.4 \%$ vs $4.7 \% ; P=.01)$. The adjusted analysis from this study showed significant reductions in adverse events (OR 0.35; 95\% $\mathrm{Cl} 0.165-0.739 ; P=.006)$ and hospitalization costs $(\$ 8,761 \pm \$ 5,956$ vs $\$ 9,848 \pm \$ 6,581 ; P<$ .001) for paracentesis with ultrasound guidance versus without such guidance. Additionally, the adjusted average length of stay was 0.2 days shorter for paracentesis with ultrasound guidance versus that without guidance (5.6 days vs 5.8 days; $P<.0001) .{ }^{44}$ Similar conclusions were reached by Mercaldi et al., who conducted a retrospective study of 69,859 patients who underwent paracentesis. Fewer bleeding complications occurred when paracentesis was performed with ultrasound guidance $(0.27 \%)$ versus without ultrasound guidance (1.27\%). Hospitalization costs increased by $\$ 19,066(P<.0001)$ and length of stay increased by 4.3 days $(P<.0001)$ for patients when paracentesis was complicated by bleeding. ${ }^{43}$ Because both of these studies were retrospective reviews of administrative databases, associations between procedures, complications, and use of ultrasound may be limited by erroneous coding and documentation.

Second, regarding technique, it is unknown whether the use of real-time ultrasound guidance confers additional benefits compared with use of static ultrasound to mark a suitable needle insertion site. In clinical practice, real-time ultrasound guidance is used to sample small fluid collections, particularly when loops of bowel or a solid organ are nearby. It is possible that higher procedural success rates and lower complication rates may be demonstrated in these scenarios in future studies.

Third, the optimal approach to train providers to perform ultrasound-guided paracentesis is unknown. While short training sessions have shown high uptake of essential skills to perform ultrasound-guided paracentesis, data regarding the effectiveness of training using a comprehensive competency assessment are limited. Simulation-based mastery learning as a means to obtain competency for paracentesis has been described in one study, ${ }^{88}$ but the translation of competency demonstrated by simulation to actual patient outcomes has not been studied. Furthermore, the most effective method to train providers who are proficient in landmark-based paracentesis to achieve competency in ultrasound-guided paracentesis has not been well studied.

Fourth, the optimal technique for identifying blood vessels 
in the abdominal wall is unknown. We have proposed that color flow Doppler should be used to identify and avoid puncture of superficial vessels, but power Doppler is three times more sensitive at detecting blood vessels, especially at low velocities, such as in veins independent of direction or flow. ${ }^{93}$ Hence using power Doppler instead of color flow Doppler may further improve the ability to identify and avoid superficial vessels along the needle trajectory. ${ }^{92}$

Finally, the impact of ultrasound use on patient experience has yet to be studied. Some studies in the literature show high patient satisfaction with use of ultrasound at the bedside, ${ }^{94,95}$ but patient satisfaction with ultrasound-guided paracentesis has not been compared directly with the landmark-based technique.

\section{CONCLUSIONS}

The use of ultrasound guidance for paracentesis has been associated with higher success rates and lower complication rates. Ultrasound is superior to physical examination in assessing the presence and volume of ascites, and determining the optimal needle insertion site to avoid inadvertent injury to abdominal wall blood vessels. Hospitalists can attain competence in ultrasound-guided paracentesis through the use of various training methods, including lectures, simulation-based practice, and hands-on training. Ongoing use and training over time is necessary to maintain competence.

\section{Acknowledgments}

The authors thank all the members of the Society of Hospital Medicine Pointof-care Ultrasound Task Force and the Education Committee members for their time and dedication to develop these guidelines.

SHM Point-of-care Ultrasound Task Force: CHAIRS: Nilam Soni, Ricardo Franco

\section{References}

1. Duszak R, Jr., Chatterjee AR, Schneider DA. National fluid shifts: fifteen-year trends in paracentesis and thoracentesis procedures. J Am Coll Radiol. 2010;7(11):859-864. doi: 10.1016/j.jacr.2010.04.013.

2. O'Brien CR, Chang J, Campos RA, et al. Characterizing the safety of paracentesis in hospitalized patients with cirrhosis and ascites from 2004-2012 in the United States. Gastroenterology. 2016;150(4). https:/doi.org /10.1016/ S0016-5085(16)32196-5

3. Gaetano JN, Micic D, Aronsohn A, et al. The benefit of paracentesis on hospitalized adults with cirrhosis and ascites. J Gastroenterol Hepatol. 2016;31(5):1025-1030. doi: 10.1016/S0016-5085(16)32196-5

4. Orman ES, Hayashi PH, Bataller R, Barritt AS. Paracentesis is associated with reduced mortality in patients hospitalized with cirrhosis and ascites. Clin Gastroenterol Hepatol. 2014;12(3):496-503.e1. doi: 10.1016/j.cgh.2013.08.025.

5. Mallory A, Schaefer JW. Complications of diagnostic paracentesis in patients with liver disease. JAMA. 1978;239(7):628-630. doi: 10.1001/ jama.1978.03280340048020.

6. Pache I, Bilodeau M. Severe haemorrhage following abdominal paracentesis for ascites in patients with liver disease. Aliment Pharmacol Ther 2005;21(5):525-529. doi: 10.1111/j.1365-2036.2005.02387.x.

7. Shekhar C, Ramakrishnan A, Claridge LC. Paracentesis: UK trainees' practice, experience and attitudes. Gut. 2013;62:A42. doi: 10.1136/gutjnl-2013-304907.096.

8. De Gottardi A, Thevenot T, Spahr L, et al. Risk of complications after abdominal paracentesis in cirrhotic patients: a prospective study. Clin Gastroenterol Hepatol. 2009;7(8):906-909. doi: 10.1016/j.cgh.2009.05.004.

9. Sharzehi K, Jain V, Naveed A, Schreibman I. Hemorrhagic complications of paracentesis: a systematic review of the literature. Gastroenterol Res Pract. 2014;2014:985141. doi: 10.1155/2014/985141.

10. Sekiguchi H, Suzuki J, Daniels CE. Making paracentesis safer: a proposal for
Sadud, Jeff Bates. WORKING GROUPS: Thoracentesis Working Group: Ria Dancel (chair), Daniel Schnobrich, Nitin Puri. Vascular Access Working Group: Ricardo Franco (chair), Benji Matthews, Saaid Abdel-Ghani, Sophia Rodgers, Martin Perez, Daniel Schnobrich. Paracentesis Working Group: Joel Cho (chair), Benji Mathews, Kreegan Reierson, Anjali Bhagra, Trevor P. Jensen. Lumbar Puncture Working Group: Nilam J. Soni (chair), Ricardo Franco, Gerard Salame, Josh Lenchus, Venkat Kalidindi, Ketino Kobaidze. Credentialing Working Group: Brian P Lucas (chair), David Tierney, Trevor P. Jensen PEER REVIEWERS Robert Arntfield, Michael Blaivas, Richard Hoppmann, Paul Mayo, Vicki Noble, Aliaksei Pustavoitau, Kirk Spencer, Vivek Tayal. METHODOLOGIST: Mahmoud El Barbary. LIBRARIAN: Loretta Grikis. SOCIETY OF HOSPITAL MEDICINE EDUCATION COMMITTEE: Daniel Brotman (past chair), Satyen Nichani (current chair), Susan Hunt. SOCIETY OF HOSPITAL MEDICINE STAFF: Nick Marzano.

${ }^{\star *}$ Collaborators of the Society of Hospital Medicine Point-of-care Ultrasound Task Force: Saaid Abdel-Ghani, Robert Arntfield, Jeffrey Bates, Michael Blaivas, Dan Brotman, Carolina Candotti, Richard Hoppmann, Susan Hunt, Venkat Kalidindi, Ketino Kobaidze, Josh Lenchus, Paul Mayo, Satyen Nichani, Vicki Noble, Martin Perez, Nitin Puri, Aliaksei Pustavoitau, Sophia Rodgers, Gerard Salame, Daniel Schnobrich, Kirk Spencer, Vivek Tayal, David M. Tierney

Disclaimer: The contents of this publication do not represent the views of the U.S. Department of Veterans Affairs or the United States Government.

Disclosures: Mr. Mader reports grants from Department of Veterans Affairs during the conduct of the study. Dr. Soni reports grants from the Department of Veterans Affairs Quality Enhancement Research Initiative (QUERI) Partnered Evaluation Initiative Grant (HX002263-01A1) outside of the submitted work. In addition, Dr. Soni receives royalties from Elsevier-Saunders. All other authors have nothing to disclose.

Funding: Brian P Lucas: Department of Veterans Affairs, Veterans Health Administration, Office of Research and Development and Dartmouth SYNERGY National Institutes of Health, National Center for Translational Science (UL1TR001086). Nilam Soni: Department of Veterans Affairs, Quality Enhancement Research Initiative (QUERI) Partnered Evaluation Initiative Grant (HX00226301A1), outside the submitted work. )

the use of bedside abdominal and vascular ultrasonography to prevent a fatal complication. Chest. 2013;143(4):1136-1139. doi: 10.1378/chest.12-0871.

11. Soyuncu S, Cete Y, Bozan H, Kartal M, Akyol AJ. Accuracy of physical and ultrasonographic examinations by emergency physicians for the early diagnosis of intraabdominal haemorrhage in blunt abdominal trauma. Injury. 2007;38(5):564-569. doi: 10.1016/j.injury.2007.01.010.

12. Chongtham DS, Singh MM, Kalantri SP, Pathak S, Jain AP. Accuracy of clinical manoeuvres in detection of minimal ascites. Indian J Med Sci. 1998;52(11):514-520.

13. Ennis J, Schultz G, Perera P, Williams S, Gharahbaghian L, Mandavia D. UItrasound for detection of ascites and for guidance of the paracentesis procedure: technique and review of the literature. Int J Clin Med. 2014;5:12771293. doi: 10.4236/ijcm.2014.520163.

14. Szabo TL, Lewin PA. Ultrasound transducer selection in clinical imaging practice. J Ultrasound Med. 2013;32(4):573-582. doi: 10.7863/jum.2013.32.4.573.

15. Stone JC, Moak JH. Feasibility of sonographic localization of the inferior epigastric artery before ultrasound-guided paracentesis. Am J Emerg Med. 2015;33(12):1795-1798. doi: 10.1016/j.ajem.2015.06.067.

16. Yeh HC, Wolf BS. Ultrasonography in ascites. Radiology. 1977;124(3):783-790. doi: 10.1148/124.3.783.

17. Lucas BP, Asbury JK, Wang Y, et al. Impact of a bedside procedure service on general medicine inpatients: a firm-based trial. J Hosp Med. 2007;2(3):143149. doi: 10.1002/jhm.159.

18. Kim JJ, Tsukamoto MM, Mathur AK, et al. Delayed paracentesis is associated with increased in-hospital mortality in patients with spontaneous bacterial peritonitis. Am J Gastroenterol. 2014;109(9):1436-1442. doi: 10.1038/ ajg.2014.212.

19. Arora S, Cheung A, Tarique U, Agarwal A, Firdouse M, Ailon J. First-year medical students use of ultrasound or physical examination to diagnose 
hepatomegaly and ascites: a randomized controlled trial. J Ultrasound. 2017;20(3):199-204. doi: 10.1007/s40477-017-0261-6.

20. Nazeer SR, Dewbre H, Miller AH. Ultrasound-assisted paracentesis performed by emergency physicians vs the traditional technique: a prospective, randomized study. Am J Emerg Med. 2005;23(3):363-367. doi: 10.1016/j. ajem.2004.11.001.

21. Kotagal M, Quiroga E, Ruffatto BJ, et al. Impact of point-of-care ultrasound training on surgical residents' confidence. J Surg Educ. 2015;72(4):e82-87. doi: 10.1016/j.jsurg.2015.01.021.

22. Martin R, Gannon D, Riggle J, et al. A comprehensive workshop using simulation to train internal medicine residents in bedside procedures performed by internists. Chest. 2012;142(4):545A. doi: 10.1378/chest.1390093.

23. Quddus A, Minami T, Summerhill E. Impact of a short 3-hour ultrasound training workshop for internal medicine residents. Chest. 2014;146(4): 509A doi: 10.1378/chest.1989267.

24. Lanoix R, Leak LV, Gaeta T, Gernsheimer JR. A preliminary evaluation of emergency ultrasound in the setting of an emergency medicine training program. Am J Emerg Med. 2000;18(1):41-45. doi: 10.1016/S0735-6757(00)90046-9.

25. Dulohery MM, Eaton J, Tajouri T, Bhagra A. Ultrasound for internal medicine physicians: the future of physical exam. J Ultrasound Med. 2014;33(6):10051011. doi: 10.7863/ultra.33.6.1005

26. Lanoix R, Baker WE, Mele JM, Dharmarajan L. Evaluation of an instructiona model for emergency ultrasonography. Acad Emerg Med. 1998;5(1):58-63. doi: 10.1111/j.1553-2712.1998.tb02576.x.

27. Terkamp C, Kirchner G, Wedemeyer J, et al. Simulation of abdomen sonography. Evaluation of a new ultrasound simulator. Ultraschall Med. 2003;24(4):239-234. doi: 10.1055/s-2003-41713.

28. Barsuk JH, Cohen ER, Potts S, et al. Dissemination of a simulation-based mastery learning intervention reduces central line-associated bloodstream infections. BMJ Qual Saf. 2014;23(9):749-756. doi: 10.1136/bmjqs-2013-002665.

29. Barsuk JH, Cohen ER, Feinglass J, McGaghie WC, Wayne DB. Clinical outcomes after bedside and interventional radiology paracentesis procedures. Am J Med. 2013;126(4):349-356. doi: 10.1016/j.amjmed.2012.09.016.

30. Fitch K, Bernstein SJ, Aguilar MD, et al. The RAND/UCLA Appropriateness Method User's Manual. Santa Monica, CA: Rand Corp.; 2001.

31. Bard C, Lafortune M, Breton G. Ascites: ultrasound guidance or blind paracentesis? CMAJ. 1986:135(3):209-210. doi: 10.1016/0736-4679(87)90268-X.

32. Sudulagunta SR, Sodalagunta MB, Bangalore Raja SK, Khorram H, Sepehrar M, Noroozpour Z. Clinical profile and complications of paracentesis in refractory ascites patients with cirrhosis. Gastroenterol Res. 2015;8(3-4):228 233. doi: $10.14740 / g r 661 w$

33. Lin S, Wang M, Zhu Y, et al. Hemorrhagic complications following abdominal paracentesis in acute on chronic liver failure: a propensity score analysis. Medicine (Baltimore). 2015;94(49):e2225. doi: 10.1097/MD.0000000000002225.

34. Lam EY, McLafferty RB, Taylor LM, Jr., et al. Inferior epigastric artery pseudoaneurysm: a complication of paracentesis. J Vasc Surg. 1998;28(3):566-569. doi: 10.1016/S0741-5214(98)70147-8.

35. Cervini P, Hesley GK, Thompson RL, Sampathkumar P, Knudsen JM. Incidence of infectious complications after an ultrasound-guided intervention. AJR Am J Roentgenol. 2010;195(4):846-850. doi: 10.2214/AJR.09.3168.

36. Wiese SS, Mortensen C, Bendtsen F. Few complications after paracentesis in patients with cirrhosis and refractory ascites. Dan Med Bull. 2011;58(1):A4212

37. Jakobson DJ, Shemesh I. Merging ultrasound in the intensive care routine. Isr Med Assoc J. 2013;15(11):688-692.

38. Landers A, Ryan B. The use of bedside ultrasound and community-based paracentesis in a palliative care service. J Prim Health Care. 2014;6(2):148-151.

39. Lin CH, Shih FY, Ma MH, Chiang WC, Yang CW, Ko PC. Should bleeding tendency deter abdominal paracentesis? Dig Liver Dis. 2005;37(12):946-951. doi: 10.1016/j.dld.2005.07.009

40. Kurup AN, Lekah A, Reardon ST, et al. Bleeding rate for ultrasound-guided paracentesis in thrombocytopenic patients. J Ultrasound Med. 2015;34(10):1833-1838. doi: 10.7863/ultra.14.10034.

41. Reardon S, Atwell TD, Lekah A. Major bleeding complication rate of ultrasound-guided paracentesis in thrombocytopenic patients. J Vasc Interv Radiol. 2013;24(4):S56. doi: 10.1016/j.jvir.2013.01.129

42. Czul F, Prager M, Lenchus J. Intra-procedural risk of bleeding associated with ultrasound guided paracentesis in patients with abnormal coagulation studies: 1907. Hepatology. 2011;54(4):1259A.

43. Mercaldi CJ, Lanes SF. Ultrasound guidance decreases complications and improves the cost of care among patients undergoing thoracentesis and paracentesis. Chest. 2013;143(2):532-538. doi: 10.1378/chest.12-0447.

44. Patel PA, Ernst FR, Gunnarsson CL. Evaluation of hospital complications and costs associated with using ultrasound guidance during abdominal paracentesis procedures. J Med Econ. 2012;15(1):1-7. doi: $10.3111 / 13696998.2011 .628723$
45. Nicolaou S, Talsky A, Khashoggi K, Venu V. Ultrasound-guided interventional radiology in critical care. Crit Care Med. 2007;35(5 Suppl):S186-197. doi: 10.1097/01.CCM.0000260630.68855.DF.

46. Conduit B, Wesley E, Christie J, Thalheimer U. PTU-002 Large volume paracentesis (LVP) can be safely performed by junior doctors without ultrasound guidance. Gut. 2013;62:A42. doi: 10.1136/gutjnl-2013-304907.095.

47. Williams JW, Jr., Simel DL. The rational clinical examination. Does this patient have ascites? How to divine fluid in the abdomen. JAMA. 1992;267(19):26452648. doi: 10.1001/jama.1992.03480190087038.

48. Rodriguez A, DuPriest RW, Jr., Shatney CH. Recognition of intra-abdominal injury in blunt trauma victims. A prospective study comparing physical examination with peritoneal lavage. Am Surg. 1982;48(9):457-459.

49. McGibbon A, Chen GI, Peltekian KM, van Zanten SV. An evidence-based manual for abdominal paracentesis. Dig Dis Sci. 2007;52(12):3307-3315. doi: 10.1007/s10620-007-9805-5

50. Cattau EL, Jr., Benjamin SB, Knuff TE, Castell DO. The accuracy of the physical examination in the diagnosis of suspected ascites. JAMA. 1982;247(8):11641166. doi: 10.1001/jama.1982.03320330060027

51. Ali J, Rozycki GS, Campbell JP, Boulanger BR, Waddell JP, Gana TJ. Trauma ultrasound workshop improves physician detection of peritoneal and pericardial fluid. J Surg Res. 1996;63(1):275-279. doi: 10.1006/jsre.1996.0260.

52. Von Kuenssberg Jehle D, Stiller G, Wagner D. Sensitivity in detecting free intraperitoneal fluid with the pelvic views of the FAST exam. Am J Emerg Med. 2003:21(6):476-478. doi: 10.1016/S0735-6757(03)00162-1

53. Goldberg BB, Goodman GA, Clearfield HR. Evaluation of ascites by ultrasound. Radiology. 1970:96(1):15-22. doi: 10.1148/96.1.15

54. Branney SW, Wolfe RE, Moore EE, et al. Quantitative sensitivity of ultrasound in detecting free intraperitoneal fluid. J Trauma. 1995;39(2):375-380. doi: 10.1016/0736-4679(96)84805-0

55. Paajanen H, Lahti P, Nordback I. Sensitivity of transabdominal ultrasonography in detection of intraperitoneal fluid in humans. Eur Radiol. 1999;9(7):14231425. doi: 10.1007/s003300050861

56. Prabhakar A, Thabet A, Mueller P, Gee MS. Image-guided peritoneal access for fluid infusion in oncology patients: Indications, technique, and outcomes. J Vasc Interv Radiol. 2014;25(3):S41. doi: 10.1016/j.jvir.2013.12.100.

57. McGahan JP, Anderson MW, Walter JP. Portable real-time sonographic and needle guidance systems for aspiration and drainage. AJR Am J Roentgenol. 1986;147(6):1241-1246. doi: 10.2214/ajr.147.6.1241

58. Moses WR. Shifting dullness in the abdomen. South Med J. 1946;39(12): 985-987

59. Edell SL, Gefter WB. Ultrasonic differentiation of types of ascitic fluid. AJR Am J Roentgenol. 1979;133(1):111-114. doi: 10.2214/ajr.133.1.111.

60. Doust BD, Thompson R. Ultrasonography of abdominal fluid collections. Gastrointest Radiol. 1978;3(3):273-279. doi: 10.1007/BF01887079.

61. Beaulieu Y, Marik PE. Bedside ultrasonography in the ICU: part 2. Chest. 2005;128(3):1766-1781. doi: 10.1378/chest.128.3.1766.

62. Irshad A, Ackerman SJ, Anis M, Campbell AS, Hashmi A, Baker NL. Can the smallest depth of ascitic fluid on sonograms predict the amount of drainable fluid? J Clin Ultrasound. 2009;37(8):440-444. doi: 10.1002/jcu.20616.

63. Inadomi J, Cello JP, Koch J. Ultrasonographic determination of ascitic volume. Hepatology. 1996;24(3):549-551. doi: 10.1002/hep.510240314

64. Sideris A, Patel P, Charles HW, Park J, Feldman D, Deipolyi AR. Imaging and clinical predictors of spontaneous bacterial peritonitis diagnosed by ultrasound-guided paracentesis. Proc (Bayl Univ Med Cent). 2017;30(3):262-264. https://doi.org/10.1080/08998280.2017.11929610

65. Hatch N, Wu TS, Barr L, Roque PJ. Advanced ultrasound procedures. Crit Care Clin. 2014;30(2):305-329. doi: 10.1016/j.ccc.2013.10.005

66. Ross GJ, Kessler HB, Clair MR, Gatenby RA, Hartz WH, Ross LV. Sonographically guided paracentesis for palliation of symptomatic malignant ascites. AJR Am J Roentgenol. 1989;153(6):1309-1311. doi: 10.2214/ajr.153.6.1309.

67. Russell KW, Mone MC, Scaife CL. Umbilical paracentesis for acute hernia reduction in cirrhotic patients. BMJ Case Rep. 2013;2013. doi: 10.1136/bcr2013-201304.

68. Epstein J, Arora A, Ellis H. Surface anatomy of the inferior epigastric artery in relation to laparoscopic injury. Clin Anat. 2004;17(5):400-408. doi: 10.1002/ca.10192.

69. Suzuki J, Sekiguchi H. Laceration of inferior epigastric artery resulting in abdominal compartment syndrome: a fatal complication of paracentesis. Am J Respir Crit Care Med. 2012;185:A5974. doi: 10.1164/ajrccm-conference.2012.185.1_MeetingAbstracts.A5974

70. Saber AA, Meslemani AM, Davis R, Pimentel R. Safety zones for anterior abdominal wall entry during laparoscopy: a CT scan mapping of epigastric vessels. Ann Surg. 2004;239(2):182-185. doi: 10.1097/01.sla.0000109151.53296.07.

71. Webster ST, Brown KL, Lucey MR, Nostrant TT. Hemorrhagic complications of large volume abdominal paracentesis. Am J Gastroenterol. 1996;91(2):366-368. 
72. Todd AW. Inadvertent puncture of the inferior epigastric artery during needle biopsy with fatal outcome. Clin Radiol. 2001;56(12):989-990. doi: 10.1053/ crad.2001.0175.

73. Seidler M, Sayegh K, Roy A, Mesurolle B. A fatal complication of ultrasound-guided abdominal paracentesis. J Clin Ultrasound. 2013;41(7):457460. doi: 10.1002/jcu.22050

74. Cherry WB, Mueller PS. Rectus sheath hematoma: review of 126 cases at a single institution. Medicine (Baltimore). 2006;85(2):105-110. doi: 10.1097/01. md.0000216818.13067.5a.

75. Oelsner DH, Caldwell SH, Coles M, Driscoll CJ. Subumbilical midline vascularity of the abdominal wall in portal hypertension observed at laparoscopy. Gastrointest Endosc. 1998;47(5):388-390. doi: 10.1016/S00165107(98)70224-X

76. Krupski WC, Sumchai A, Effeney DJ, Ehrenfeld WK. The importance of abdominal wall collateral blood vessels. Planning incisions and obtaining arteriography. Arch Surg. 1984;119(7):854-857. doi: 10.1001/archsurg.1984.01390190092021.

77. Rozen WM, Ashton MW, Taylor GI. Reviewing the vascular supply of the anterior abdominal wall: redefining anatomy for increasingly refined surgery. Clin Anat. 2008;21(2):89-98. doi: 10.1002/ca.20585.

78. Adams A, Roggio A, Wilkerson RG. 368 Sonographic assessment of inadvertent vascular puncture during paracentesis using the traditional landmark approach. Ann Emerg Med. 2015;66:S132-S133. doi: 10.1016/j. annemergmed.2015.07.404

79. Barsuk JH, Rosen BT, Cohen ER, Feinglass J, Ault MJ. Vascular ultrasonography: a novel method to reduce paracentesis related major bleeding. $J$ Hosp Med. 2018;13(1):30-33. doi: 10.12788/jhm.2863.

80. Skolnick ML. Estimation of ultrasound beam width in the elevation (section thickness) plane. Radiology. 1991;180(1):286-288. doi: 10.1148/radiology.180.1.2052713

81. Keil-Rios D, Terrazas-Solis H, Gonzalez-Garay A, Sanchez-Avila JF, Garcia-Juarez I. Pocket ultrasound device as a complement to physical examination for ascites evaluation and guided paracentesis. Intern Emerg Med. 2016;11(3):461-466. doi: 10.1007/s11739-016-1406-x.

82. Kessler C, Bhandarkar S. Ultrasound training for medical students and internal medicine residents--a needs assessment. J Clin Ultrasound. 2010;38(8):401 408. doi: 10.1002/jcu.20719

83. Schnobrich DJ, Gladding S, Olson AP, Duran-Nelson A. Point-of-care ultrasound in internal medicine: a national survey of educational leadership. $J$ Grad Med Educ. 2013:5(3):498-502. doi: 10.4300/JGME-D-12-00215.1.

84. Eisen LA, Leung S, Gallagher AE, Kvetan V. Barriers to ultrasound training in critical care medicine fellowships: a survey of program directors. Crit Care
Med. 2010;38(10):1978-1983. doi: 10.1097/CCM.0b013e3181eeda53.

85. Neri L, Storti E, Lichtenstein D. Toward an ultrasound curriculum for critical care medicine. Crit Care Med. 2007;35(5 Suppl):S290-304. doi: 10.1097/01. CCM.0000260680.16213.26

86. Ma I, Arishenkoff S, Wiseman J, et al. Internal medicine point-of-care ultrasound curriculum: consensus recommendations from the Canadian Internal Medicine Ultrasound (CIMUS) Group. J Gen Intern Med. 2017;32(9):10521057. doi: 10.1007/s11606-017-4071-5.

87. Kelm D, Ratelle J, Azeem N, et al. Longitudinal ultrasound curriculum improves long-term retention among internal medicine residents. J Grad Med Educ. 2015;7(3):454-457. doi: 10.4300/JGME-14-00284.1.

88. Barsuk JH, Cohen ER, Vozenilek JA, O'Connor LM, McGaghie WC, Wayne DB. Simulation-based education with mastery learning improves paracentesis skills. J Grad Med Educ. 2012;4(1):23-27. doi: 10.4300/JGME-D-11-00161.1.

89. Lenchus JD. End of the "see one, do one, teach one" era: the next generation of invasive bedside procedural instruction. J Am Osteopath Assoc. 2010;110(6):340-346. doi: 10.7556/jaoa.2010.110.6.340

90. American Board of Internal Medicine. Policies and Procedures for Certification. Philadelphia, PA: ABIM; 2006

91. Lucas BP, Tierney DM, Jensen TP, et al. Credentialing of hospitalists in ultrasound-guided bedside procedures: a position statement of the Society of Hospital Medicine. J Hosp Med. 2018;13(2):117-125. doi: 10.12788/jhm.2917.

92. Brown GM, Otremba M, Devine LA, Gray C, Millington SJ, Ma IW. Defining competencies for ultrasound-guided bedside procedures: consensus opinions from Canadian physicians. J Ultrasound Med. 2016;35(1):129-141. doi: 10.7863/ultra.15.01063.

93. Babcock DS, Patriquin H, LaFortune M, Dauzat M. Power doppler sonography: basic principles and clinical applications in children. Pediatr Radiol. 1996;26(2):109-115. doi: 10.1007/BF01372087.

94. Howard ZD, Noble VE, Marill KA, et al. Bedside ultrasound maximizes patient satisfaction. J Emerg Med. 2014;46(1):46-53. doi: 10.1016/j. jemermed.2013.05.044.

95. Lindelius A, Torngren S, Nilsson L, Pettersson H, Adami J. Randomized clinical trial of bedside ultrasound among patients with abdominal pain in the emergency department: impact on patient satisfaction and health care consumption. Scand J Trauma Resusc Emerg Med. 2009;17:60. doi: 10.1186/1757-7241-17-60.

\section{APPENDICES}

All 5 appendices are viewable online at https://www.journalofhospitalmedicine .com. 